\title{
Frioux (Paule). L'École à l'île de La Réunion entre les
} deux guerres

(coll. École et éducation). Paris : éditions Khartala, 1999, 364 p., ISBN :

2-86537-859-4.

\section{Gérard Vigner}

\section{(2) OpenEdition}

\section{Édition électronique}

URL : https://journals.openedition.org/dhfles/2961

DOI : $10.4000 /$ dhfles. 2961

ISSN : 2221-4038

\section{Éditeur}

Société Internationale pour l'Histoire du Français Langue Étrangère ou Seconde

Édition imprimée

Date de publication : 1 décembre 2000

Pagination : 129-131

ISSN : $0992-7654$

Référence électronique

Gérard Vigner, «Frioux (Paule). L'École à l'île de La Réunion entre les deux guerres », Documents pour I'histoire du français langue étrangère ou seconde [En ligne], 25 | 2000, mis en ligne le 04 octobre 2014, consulté le 27 mai 2021. URL : http://journals.openedition.org/dhfles/2961 ; DOI : https://doi.org/ $10.4000 /$ dhfles.2961

Ce document a été généré automatiquement le 27 mai 2021.

(c) SIHFLES 


\section{Frioux (Paule). L'École à l'île de La Réunion entre les deux guerres}

(coll. École et éducation). Paris : éditions Khartala, 1999, 364 p., ISBN :

2-86537-859-4.

Gérard Vigner

\section{RÉFÉRENCE}

Frioux (Paule). L'École à l'île de La Réunion entre les deux guerres, (coll. École et éducation).

Paris : éditions Khartala, 1999, 364 p., ISBN : 2-86537-859-4.

1 Si l'histoire de l'école dans les colonies françaises est dans son ensemble mieux connue aujourd'hui par les travaux nombreux consacrés à l'école au Maghreb, en Afrique noire ou dans l'ex-Indochine, celle qui porte sur la scolarisation dans ce que l'on a appelé les « vieilles colonies » l'est beaucoup moins. On sait que par le traité de Paris du 30 mai 1814, l'Angleterre restitue à la France l'essentiel des colonies que celle-ci possédait au $1^{\mathrm{er}}$ janvier 1792. La France reprend ainsi possession, dans les Antilles, de la Martinique, de la Guadeloupe et de ses dépendances, de la partie nord de Saint-Martin, de la Guyane en Amérique du Sud, dans l'océan Indien de l'île Bourbon, qui allait devenir l'île de la Réunion, les Anglais conservant cependant l'île Maurice, ainsi que les cinq comptoirs de l'Inde et en Afrique des comptoirs de Saint- Louis et de Gorée au Sénégal. Ces « vieilles colonies » connurent un sort à part dans l'empire colonial français et bénéficièrent d'un statut spécifique qui leur permirent, pour certaines d'entre elles, de devenir par la loi du 19 mars 1946 des départements d'outre-mer (D.O.M.), d'autres des territoires d'outre-mer (T.O.M.), statut qui les plaça en dehors du processus de décolonisation qui affecta cet empire entre 1954 et 1962, dans des conditions souvent dramatiques (de la fin de la guerre d'Indochine à la fin de la guerre d'Algérie). Pour ces raisons, l'école resta, aux formes nécessaires d'adaptation près, régie par des programmes métropolitains, à la différence des autres colonies où se mit en place, jusqu'en $1945 \mathrm{au}$ moins, un double réseau de scolarisation, celui destiné aux populations indigènes et 
celui réservé aux populations d'origine européenne. Peut-être faut-il voir dans cette situation, apparemment proche de ce qui se pratiquait en métropole, les raisons d'un moindre intérêt des chercheurs pour des territoires où le rôle de l'école dans la diffusion du français mérite cependant d'être examiné de plus près.

2 L'ouvrage en question ne saurait être considéré comme un ouvrage d'historien au sens où sous la plume d'un seul chercheur seraient rassemblés toutes les informations, tous les faits pouvant s'inscrire dans la perspective envisagée. Il se fonde sur le recueil des témoignages de 130 personnes qui ont interrogé leurs souvenirs d'écoliers de l'entredeux-guerres, mémoire vivante qui, confrontée aux éléments d'informations pris dans les archives, dans différents documents statistiques, permet de dessiner de l'intérieur le portrait de cette " école-longtemps ", telle que les Réunionnais l'ont plaisamment baptisée. L'ouvrage est organisé en quatre grandes parties : "Qui va à l'école ? Comment ? Pourquoi ? ", "Que se passe-t-il dans les écoles ? ", "Instruction et francophonie ", «L'école-longtemps et la modernité ». Les différents témoignages ont été ainsi ventilés dans différents chapitres qui permettent de rendre compte d'une réalité scolaire où, à la précarité des conditions matérielles, répond une très grande fragilité des apprentissages qui y sont dispensés. La très grande pauvreté des populations fait que la fréquentation scolaire s'y accomplit de façon très sporadique et où très souvent les enfants sont sommés, comme en métropole à la fin du XIX ${ }^{\mathrm{e}}$ siècle, de choisir entre le travail aux champs ou à la maison et le travail à l'école. Arbitrage, on s'en doute, qui ne se fait pas toujours en faveur de l'école. La problématique de l'ouvrage s'organise autour de la question de savoir si « l'école-longtemps » est restée une école reproduisant la hiérarchie de l'ordre colonial, ou si elle a permis d'amorcer une transformation de la société réunionnaise. Les témoignages semblent plaider en faveur de cette seconde hypothèse. Pour ce qui peut nous intéresser ici plus directement, c'est à dire les objectifs et conditions d'enseignement du français, les témoignages s'organisent tous autour de la relation entre le créole, langue du quotidien, souvent la seule langue connue et pratiquée, et le français, la langue de l'école, la langue d'enseignement, langue difficile à apprendre, source de nombreux échecs. On ne peut s'empêcher de penser à la situation de l'enseignement du français dans les écoles de la métropole, en zone rurale, auprès d'enfants allophones. Recours à la méthode directe, un enseignement de l'oral qui est plus un fiançais récité qu'un oral vivant, une forte prédominance de l'écrit, l'importance de la dictée, exercice emblématique présent dans toutes les mémoires. Mais aussi le problème de la place du créole dans la classe. Officiellement prohibée, la langue locale semble avoir été couramment utilisée dans les écoles. Témoignages qui recoupent ceux qu'ont bien voulu laisser en métropole, soit d'anciens élèves, soit d'anciens instituteurs ayant enseigné dans les campagnes au début du $\mathrm{XX}^{\mathrm{e}}$ siècle (voir ainsi pour la France l'ouvrage de Jean-François Chanet, L'École républicaine et les petites patries, Aubier, 1996 et celui de Pierre Boutan, "La langue des Messieurs ». Histoire de l'enseignement du français à l'école primaire, Armand Colin, 1996). Un bilinguisme spontané s'est ainsi organisé dans les écoles devant une administration qui, dans bien des cas, préférait fermer les yeux. Cette présence du créole ne signifiait pas pour autant que cette langue était valorisée, elle était simplement utilisée comme outil d'accès au français. L'école réunionnaise de l'entre-deux- guerres reste une école coloniale par la faiblesse des moyens matériels mis à sa disposition, par un enseignement du français qui s'adresse à des populations qui se situent dans un autre univers, social, culturel, linguistique que celui pour lequel a été conçu au départ cette école. Les décalages n'en sont que plus flagrants. Mais elle 
en représente une modalité particulière, celles des écoles à programme métropolitains implantées dans les colonies, dont la connaissance, et celle des pratiques d'enseignement du français qui y étaient associées, reste encore très superficielle.

3 Cet ouvrage, même s'il s'oriente dans des directions qui se situent dans un autre champ de préoccupations que celui du seul enseignement du français et de son histoire, est cependant utile par l'éclairage qu'il apporte sur un moment de cet enseignement dans certaines colonies.

\section{AUTEURS}

\section{GÉRARD VIGNER}

Académie de Versailles 